\title{
Article \\ Swelling-Resistant, Crosslinked Polyvinyl Alcohol Membranes with High ZIF-8 Nanofiller Loadings as Effective Solid Electrolytes for Alkaline Fuel Cells
}

\author{
Po-Ya Hsu ${ }^{1,+}$, Ting-Yu Hu ${ }^{1,+}{ }^{\text {, Selvaraj Rajesh Kumar }{ }^{1} \mathbb{D}, \text { Kevin C.-W. Wu }}{ }^{2,3, * \mathbb{D}}$ and Shingjiang Jessie Lue ${ }^{1,4,5, *(\mathbb{D})}$ \\ 1 Department of Chemical and Materials Engineering, Chang Gung University, Guishan District, \\ Taoyuan City 333, Taiwan; mini50636@gmail.com (P.-Y.H.); hu70308@gmail.com (T.-Y.H.); \\ rajeshkumarnst@gmail.com (S.R.K.) \\ 2 Department of Chemical Engineering, National Taiwan University, Taipei City 106, Taiwan \\ 3 Institute of Biomedical Engineering and Nanomedicine, National Health Research Institutes, \\ Miaoli County 350, Taiwan \\ 4 Department of Safety, Health and Environment Engineering, Ming Chi University of Technology, Taishan, \\ New Taipei City 243, Taiwan \\ 5 Division of Joint Reconstruction, Department of Orthopedics, Chang Gung Memorial Hospital, Linkou, \\ Taoyuan City 333, Taiwan \\ * Correspondence: kevinwu@ntu.edu.tw (K.C.-W.W.); jessie@mail.cgu.edu.tw (S.J.L.); \\ Tel.: +886-3366-3064 (K.C.-W.W.); +886-3211-8800 (ext. 5489) (S.J.L.); Fax: +886-3211-8700 (S.J.L.) \\ + These authors contributed equally to this work.
}

\section{check for} updates

Citation: Hsu, P.-Y.; Hu, T.-Y.; Kumar, S.R.; Wu, K.C.-W.; Lue, S.J.

Swelling-Resistant, Crosslinked Polyvinyl Alcohol Membranes with High ZIF-8 Nanofiller Loadings as Effective Solid Electrolytes for Alkaline Fuel Cells. Nanomaterials 2022, 12, 865. https://doi.org/ $10.3390 /$ nano12050865

Academic Editors: Ioannis

V. Yentekakis and Sergio Brutti

Received: 6 January 2022

Accepted: 2 March 2022

Published: 4 March 2022

Publisher's Note: MDPI stays neutral with regard to jurisdictional claims in published maps and institutional affiliations.

Copyright: (C) 2022 by the authors. Licensee MDPI, Basel, Switzerland. This article is an open access article distributed under the terms and conditions of the Creative Commons Attribution (CC BY) license (https:// creativecommons.org/licenses/by/ $4.0 /)$.

\begin{abstract}
The present work investigates the direct mixing of aqueous zeolitic imidazolate framework8 (ZIF-8) suspension into a polyvinyl alcohol (PVA) and crosslinked with glutaraldehyde (GA) to form swelling-resistant, mechanically robust and conductivity retentive composite membranes. This drying-free nanofiller incorporation method enhances the homogeneous ZIF-8 distributions in the PVA/ZIF-8/GA composites to overcome the nanofiller aggregation problem in the mixed matrix membranes. Various ZIF-8 concentrations (25.4, 40.5 and $45.4 \mathrm{wt}$.\%) are used to study the suitability of the resulting GA-crosslinked composites for direct alkaline methanol fuel cell (DAMFC). Surface morphological analysis confirmed homogeneous ZIF-8 particle distribution in the GA-crosslinked composites with a defect- and crack-free structure. The increased ionic conductivity ( $21 \%$ higher than the ZIF-free base material) and suppressed alcohol permeability ( $94 \%$ lower from the base material) of PVA/40.5\%ZIF-8/GA resulted in the highest selectivity among the prepared composites. In addition, the GA-crosslinked composites' selectivity increased to 1.5-2 times that of those without crosslink. Moreover, the ZIF-8 nanofillers improved the mechanical strength and alkaline stability of the composites. This was due to the negligible volume swelling ratio $(<1.4 \%)$ of high $(>40 \%) \mathrm{ZIF}-8$ loaded composites. After $168 \mathrm{~h}$ of alkaline treatment, the PVA/40.5\%ZIF-8/GA composite had almost negligible ionic conductivity loss $(0.19 \%)$ compared with the initial material. The maximum power density $\left(\mathrm{P}_{\max }\right.$ ) of PVA/40.5\%ZIF-8/GA composite was $190.5 \mathrm{~mW} \mathrm{~cm}^{-2}$ at $60{ }^{\circ} \mathrm{C}$, an increase of $181 \%$ from the PVA/GA membrane. Moreover, the $P_{\max }$ of PVA/40.5\%ZIF-8/GA was $10 \%$ higher than that without GA crosslinking. These swelling-resistant and stable solid electrolytes are promising in alkaline fuel cell applications.
\end{abstract}

Keywords: polymeric electrolytes; ZIF-8 nanofillers; glutaraldehyde; alkaline stability; direct alkaline methanol fuel cell

\section{Introduction}

Increased environmental awareness of the need for low-polluting gas emissions makes fuel cells a popular alternative energy to fossil oil [1]. Accordingly, various renewableenergy-related systems have been developed, including solar cells, supercapacitors, metalion/metal-air batteries, and fuel cells, that have been recognized as potential energy storage 
devices [2,3]. Among these, the proton-exchange membrane (PEM) and anionic-exchange membrane (AEM) fuel cell technologies are appropriate for portable devices and energy power supply $[4,5]$. However, PEM fuel cells have limitations in mass production. The high costs of PEM membranes and metal electro-catalysts are major concerns regarding commercialization [4]. Alternatively, the alkaline fuel cells are beneficial for favorable kinetic reactions at both the cathode and the anode [6-9]. Cost-effective catalysts, such as non-noble metals, metal oxides, and carbonaceous nanocomposites, can be used as effective electro-catalysts [10-12]. Moreover, an alkaline solution is advantageous for higher power density $\left(P_{\max }\right)$ due to the higher catalytic efficiency and a higher rate of fuel oxidation process than that of acidic medium [13]. Therefore, alkaline fuel cells are more economically feasible than the proton-exchange counterpart.

Direct methanol fuel cells (DMFC) are studied next to hydrogen fuel cells due to their low cost and high supply quantity. It was reported that the methanol oxidation rate in the alkali medium is faster than in acidic environment [14]. The opposite transport of $\mathrm{OH}^{-}$ions from the cathode region into the anode section can suppress methanol crossover. A significant improvement in the water management system (as water is produced at anode compartment) alleviates the cathode flooding issue. Moreover, non-platinum catalyst materials are available in the DMFC [15].

Although many AEMs are developed for alkaline fuel cells, there are still challenges to overcome. The compromise between ionic conductivity and fuel cross-over is the main concern. High conductivity and low fuel permeability are unlikely to be achieved at the same time. We reported that mixed matrix membranes (MMMs) with nanofillers in polymers are an easy approach to simultaneously obtain highly conductive composites to retard fuel cross-over [16,17]. Among these polymers, polyvinyl alcohol (PVA) is a nontoxic synthetic polymer, exhibits favorable reactivity for crosslinking, has a more hydrophilic nature, and possesses eco-friendly characteristics. The ease of film formation and the ability to separate water from alcohol [18] also make these materials suitable for use as AEMs [19]. Moreover, the abundant OH groups in the polymer side chain give PVA a high affinity for water. Alkaline-doped PVA exhibits suppressed permeability and increased ionic conductivity due to the increased amorphous region after filler incorporation. This was characterized in suitable free volume, which allows water permeation but inhibits large alcohol molecules $[14,16]$. Researchers have recently paid more attention to improving the $P_{\max }$ for DMFC by optimizing the catalyst loadings, effects of temperature, alcohol concentrations and acidic vs. alkaline doped electrolytes. Some typical literature results are summarized in Table S1.

The mechanical strength of PVA membranes always becomes poor after long-term operation because of swelling in aqueous solutions [20]. It has been demonstrated that the existence of a crosslinker into the PVA polymeric matrix improves the mechanical strength [21,22]. Furthermore, Diaz et al. [23] reported that after a post-crosslinked polyvinyl alcohol/polybenzimadazole (PVA/PBI) composite was immersed in $\mathrm{KOH}$ solution for 7 days, there was no change in the membrane except for the color, while the un-crosslinked PVA/PBI membrane became brittle. Merle et al. [22] proposed that precrosslinked PVA maintained its integrity and did not experience a color change when doped in $1 \mathrm{M}$ potassium hydroxide $(\mathrm{KOH})$ at ambient temperature for one month, demonstrating the high tolerance of this material to an alkaline environment.

However, this crosslinked polymer becomes mechanically stable at the expense of its ionic conductivity. PVA reacts with glutaraldehyde (GA) crosslinker, and the hydroxyl groups in PVA are consumed [24]. In addition, the PVA structure becomes constrained, restricting molecules from diffusing and reducing fuel crossover through the membrane. That also implies less water and $\mathrm{KOH}$ adsorption in the polymer [23]. Rudra [25] et al. prepared pre-crosslinked PVA with GA, and the results found that the water uptake and degree of membrane swelling reduced as compared with un-crosslinked samples. In our previous research, the quaternized PVA (QPVA)/GO-Fe $\mathrm{O}_{4}$ composites were placed in the GA crosslinking solution and the post-crosslinked QPVA membrane exhibited a lower solubility 
in hot water at $60^{\circ} \mathrm{C}$ than the pre-crosslinked membrane (i.e., GA in PVA solution before cast and drying). The suppression of swelling in this post-crosslinked QPVA confirmed the membrane stability in water. The ionic conductivity of the GA-crosslinked QPVA/GO$\mathrm{Fe}_{3} \mathrm{O}_{4}$ composite was $0.0076-0.0108 \mathrm{~S} \mathrm{~cm}^{-1}$ [26], which was drastically lower than those of the un-crosslinked QPVA/GO- $\mathrm{Fe}_{3} \mathrm{O}_{4}$ composite membranes $\left(0.0468-0.0548 \mathrm{~S} \mathrm{~cm}^{-1}\right)$ [27]. Decreased direct alkaline methanol fuel cells (DAMFC) performance was observed using the GA-crosslinked QPVA/GO-Fe $\mathrm{O}_{4}$ membrane [26]. We suspect that nanofiller aggregation in the QPVA/GO- $\mathrm{Fe}_{3} \mathrm{O}_{4}$ composite membrane induced crack formation between the polymer and fillers, which caused voids and defects, leading to undesirable properties $[18,28,29]$.

Homogeneous mixtures are required to prepare MMMs with good compatibility between the fillers and polymers. Deng et al. [30] developed a water-based technique to synthesize ZIF-8 particles and mix ZIF-8 aqueous slurry with PVA solution to promote good nanofillers dispersion in PVA matrices without particle aggregates. Using that protocol, we report on the presence of porous ZIF-8 nanofillers in a polymeric matrix that improves the $\mathrm{OH}^{-}$conductivity and suppresses alcohol permeability. However, the composite membrane stability in the $\mathrm{KOH}$ solution is not sufficient over long-term operations. The ionic conductivity decreased by $\sim 32 \%$ after the composite was placed in a $6 \mathrm{M} \mathrm{KOH}$ solution for $168 \mathrm{~h}$ [31].

We attempted to crosslink the PVA/ZIF-8 composite with homogeneous ZIF-8 nanofiller distribution. This is performed by mixing ZIF- 8 suspension and an aqueous PVA solution and crosslinked with GA for alkaline stability. The membrane characteristics of the pre-crosslinked PVA/ZIF-8/GA composites with various ZIF-8 loads are studied. The selectivities of GAcrosslinked composites were greater than those of the un-crosslinked samples. The stability in alkaline, volume swelling ratio, ionic conductivity, and mechanical strength of these composites are improved in crosslinked composites. The DAMFC performance using the proposed composites with various ZIF-8 loads is evaluated, and the effects of filler load and GA crosslinking are discussed.

\section{Materials and Methods}

\subsection{Materials}

Zinc nitrate hexahydrate $\left(\mathrm{Zn}\left(\mathrm{NO}_{3}\right)_{2} 6 \mathrm{H}_{2} \mathrm{O}\right)$ was obtained from Acros Organics (Morris Plains, NJ, USA). Polyvinyl alcohol (PVA, 99\% hydrolyzed, 146-186 k Da), 2-methylimidazole, potassium hydroxide $(\mathrm{KOH})$, hydrochloric acid $(\mathrm{HCl}, 37 \%)$ glutaraldehyde $(\mathrm{GA})$, Nafion, and methanol were acquired from Sigma-Aldrich (St. Louis, MO, USA).

\subsection{Preparation of GA-Crosslinked PVA/ZIF-8 Composites}

2-methylimidazole $(18 \mathrm{~g})$ and $\mathrm{Zn}\left(\mathrm{NO}_{3}\right)_{2} 6 \mathrm{H}_{2} \mathrm{O}(1 \mathrm{~g})$ were mixed in $60 \mathrm{~mL}$ of deionized (DI) water to form ZIF-8 suspension through the water-based coprecipitation method. The aqueous PVA solution was added with $25.4 \%$ of ZIF-8 particle suspensions to form PVA/ZIF-8 mixed solutions [30]. A $0.25 \mathrm{~g}$ crosslinker solution (1.5 wt.\% GA, $1 \mathrm{wt} . \%$ sulfuric acid, and $97.5 \mathrm{wt} . \%$ water) was mixed with the above solution under continuous stirring for $30 \mathrm{~min}$. Then, the solution was cast on the surface of the glass substrate using an application knife (clearance of $600 \mu \mathrm{m}$ ). The PVA/ZIF-8/GA composite was placed in a vacuum oven and dried at $80^{\circ} \mathrm{C}$. Different concentrations (40.5 and $45.4 \mathrm{wt} . \%$ ) of ZIF-8 nanofillers were prepared in the PVA polymeric matrix using a similar procedure. The thickness of the dried sample was measured to be $40-45 \mu \mathrm{m}$.

\subsection{Physical-Chemical Properties}

The morphological properties of PVA/GA and PVA/ZIF-8/GA composites were studied using field emission scanning electron microscopy (FESEM, model JSM-7500F, Hitachi High-Technologies Corp., Tokyo, Japan) and transmission electron microscope (TEM, model TECNAI-20, New York, NY, USA). The elemental composition was determined using energy dispersive X-ray spectroscopy (EDS) attached with FESEM and X-ray photoelectron 
spectroscopy (Thermo Scientific ${ }^{\mathrm{TM}} \mathrm{K}-\mathrm{Alpha}{ }^{\mathrm{TM}}$ XPS, Thermo Fisher Scientific, Waltham, MA, USA). The specific surface area and pore size distribution of the ZIF-8 nanoparticle were examined using nitrogen adsorption-desorption isotherm measurements (Micomeritics ASAP2020, Norcross, GA, USA). The phase purity of the PVA/GA and PVA/ZIF-8/GA composites was determined using X-ray diffraction (XRD, model D5005D, Siemens AG, Munich, Germany). The chemical structure of the samples was determined using Fourier transform infrared spectroscopy (FTIR, Model Spectrum 100, Perkin- Elmer Inc., Shelton, CT, USA). The degree of crystallinities was estimated by means of differential scanning calorimetry (DSC, Perkin- Elmer Inc., Shelton, CT, USA) under a nitrogen atmosphere. The polymeric crystallinity was calculated using the below equation

$$
\chi_{\mathrm{C}}=\frac{\Delta \mathrm{H}}{\Delta \mathrm{H}_{\mathrm{C}}(1-\Phi)}
$$

where $\Delta \mathrm{H}$ is the melting enthalpy data of the polymeric composite, $\Delta \mathrm{H}_{\mathrm{c}}$ represents the melting enthalpy, and $\Phi$ is the loading amount (in wt.\%) of ZIF-8 nanofillers in the composite membrane [32]. The mechanical behaviors of the composites were analyzed using a tensile-strength tester (model AI-3000, Gotech Testing Machines Inc., Taichung, Taiwan) at ambient temperature [33]. Elongation at break; tensile strength; and Young's modulus were reported. The alkaline uptakes, swelling ratios, ionic conductivities, and methanol permeabilities were measured according to previous procedures $[14,16,29,31,34]$ after the composites were doped with $6 \mathrm{M} \mathrm{KOH}$ solution to form hydroxide-conductive electrolytes.

\subsection{Single-Cell Measurement}

The experimental setup for single-cell measurement was detailed in our previous work $[14,16,29,31,34]$. To evaluate the cell performance, the PVA/GA/ZIF-8 composites were dried and placed in a $6 \mathrm{M}$ alkali solution for at least $12 \mathrm{~h}$. The $1.5 \times 1.5 \mathrm{~cm}^{2}$ PVA/GA/ZIF-8 composites were placed between two gas diffusion electrodes (GDEs) to set up a membrane electrode assembly (MEA) with a $1 \mathrm{~cm}^{2}$ active area. The GDEs consisted of carbon cloth sprayed with $\mathrm{Pt}-\mathrm{Ru} / \mathrm{C}\left(2 \mathrm{mg} \mathrm{cm}^{2}\right)$ for the anode and $\mathrm{Pt} / \mathrm{C}\left(1 \mathrm{mg} \mathrm{cm}{ }^{2}\right)$ for the GDE cathode, with the catalyst layers facing the electrolyte membrane. To prevent liquid fuel leakage, Teflon gaskets were fixed between the carved flow field plates and surrounded the MEA. Conductive end plates (thickness of $10 \mathrm{~mm}$ ) were placed next to the flow field plates [14]. The $2 \mathrm{M}$ methanol/6 $\mathrm{M} \mathrm{KOH}$ solution was used as the anode feed (at a flow rate of $5 \mathrm{~mL} \mathrm{~min}^{-1}$ ). Humidified oxygen gas was fed into the cathode at a flow rate of $100 \mathrm{~mL} \mathrm{~min}{ }^{-1}$. A constant temperature of $30^{\circ} \mathrm{C}$ or $60{ }^{\circ} \mathrm{C}$ was maintained using heating tapes adhered to the end plates and controlled through a software controller with cell temperature feedback from a thermocouple inserted into a flow field plate. An electrical load (PLZ164WA electrochemical system, Kikusui Electronics Corporation, Tokyo, Japan) was used to record the current density (I) and potential (V) values. The maximum peak-power density $\left(\mathrm{P}_{\max }\right)$ was determined from the maximum power ( $\mathrm{V}$ and I product) value.

\section{Results and Discussion}

\subsection{Morphological and EDX Mapping Analysis}

A TEM micrograph of pure ZIF-8 nanoparticles shows a cubic shape (50 to $80 \mathrm{~nm}$ ), as displayed in Figure 1a. The Brunauer-Emmett-Teller (BET) surface area (Figure S1) and Langmuir surface area of ZIF-8 nanoparticles show $1430 \mathrm{~m}^{2} \mathrm{~g}^{-1}$ and $191 \mathrm{~m}^{2} \mathrm{~g}^{-1}$, respectively. The single point total pore volume was $1.02 \mathrm{~cm}^{2} \mathrm{~g}^{-1}$. The Barrett-JoynerHalenda (BJH) adsorption average pore diameter and average pore width of the ZIF-8 particles were 21.8 and $28.6 \mathrm{~nm}$. These results confirm ZIF-8 to be a porous framework structure. The surface area and pore diameter of the ZIF-8 particles matched the description reported in the literature $[35,36]$. 

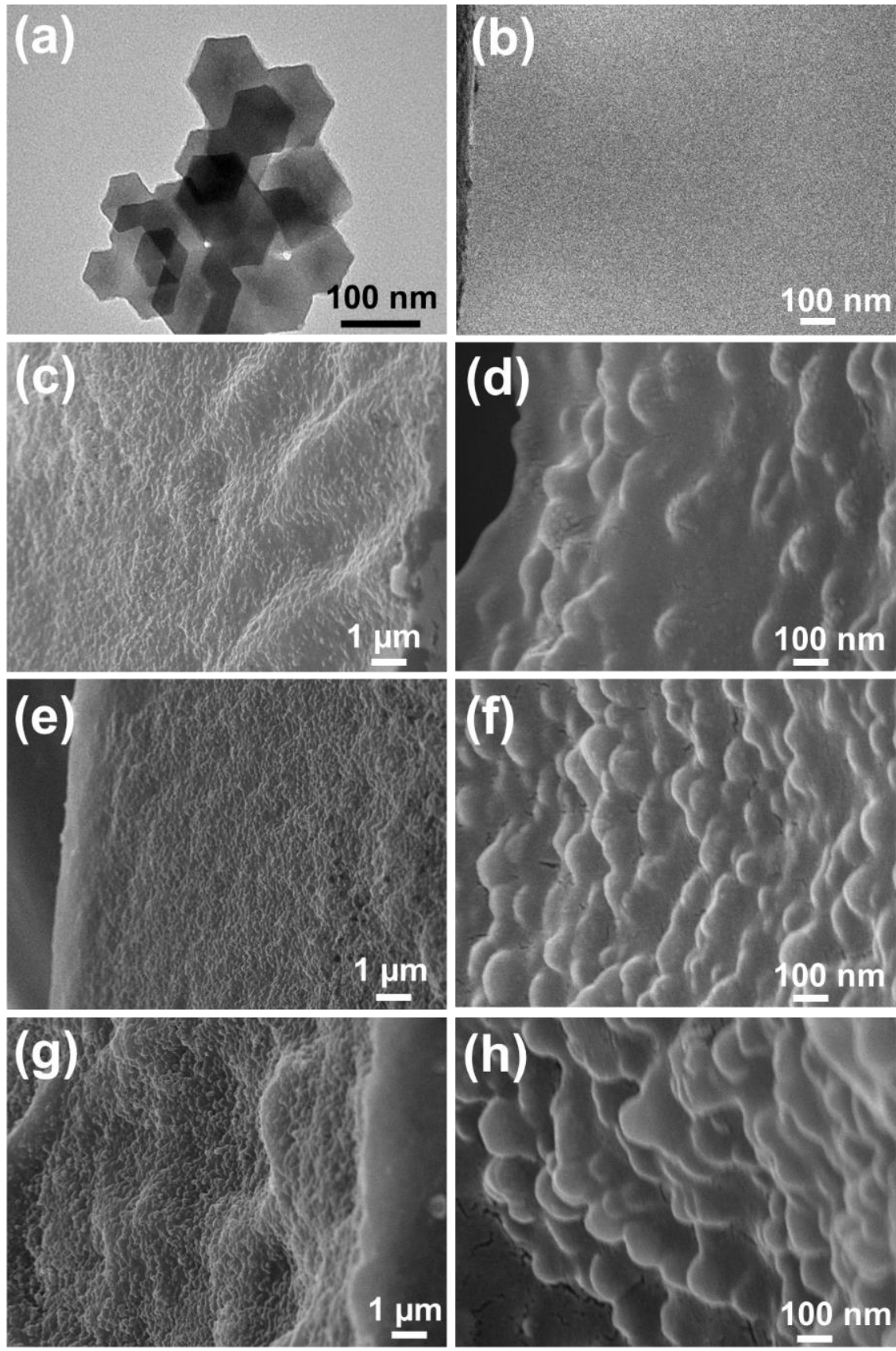

Figure 1. (a) Transmission electron microscopic image of pristine ZIF-8 nanoparticles; low and high magnification cross-sectional FESEM images of (b) PVA/GA, (c,d) PVA/25.4\%ZIF-8/GA, (e,f) PVA/40.5\%ZIF-8/GA, and (g,h) PVA/45.4\%ZIF-8/GA composite membranes.

The cross-sectional images of different ZIF-8 loadings in the PVA/ZIF-8/GA composites are displayed in Figure 1. The PVA/GA shows a dense and smooth surface morphology without any cracks, as shown in Figure 1b. Photographic images of PVA/GA also display transparent smooth film (Figure S2a). The low and higher magnified FESEM (Figure 1c-f) shows a uniform ZIF-8 nanofiller distribution in the polymeric matrix by increasing the ZIF-8 loadings from $25.4 \%$ to $40.5 \%$. Moreover, no voids or defects are shown in the composite membrane between the nanofillers and polymer matrix. This high ZIF-8 load was realized using the water-phase preparation method. Amirilargani and Sadatnia reported that 7.5-10\% of dry ZIF-8 nanofillers blended with PVA matrix lead to metal organic framework aggregation and decreased composite compactness [37]. In this work, the ZIF-8 nanoparticle aqueous solution without drying was directly mixed with the polymer. 
The ZIF-8 particles were hydrated using water molecules to distribute homogeneously in the polymeric matrices with up to $40.5 \%$ content. This was due to the excellent interfacial compatibility between water-based ZIF-8 nanofillers and polymeric matrix in the composites. Increasing the ZIF-8 nanofillers concentration (45.4\%), the ZIF-8 particle non-homogeneous distribution in the polymeric matrix was observed (Figure $1 \mathrm{~g}, \mathrm{~h}$ ). Figure S2b,c shows the corresponding surface photographic images of PVA/40.5\%ZIF-8/GA and PVA/45.4\%ZIF-8/GA composite membranes. The PVA/45.4\%ZIF-8/GA membrane had some white particles, which might be due to ZIF-8 aggregates.

The corresponding EDS mapping micrographs of $\mathrm{Zn}$ element distribution in the composites with various ZIF-8 nanofiller contents are shown in Figure S3a-c. Zn represents the existence of ZIF-8 particles in the composites. They confirmed that the ZIF-8 particles were mixed well and were evenly distributed in the composite membranes. Additionally, the $\mathrm{Zn}$ weight percentages increased (8.56\% to $15.5 \%$ ) with increasing ZIF-8 nanofiller contents, as shown in Table S2. This indicates that the composites were homogeneous at the micrometer scale.

\subsection{Structural Analysis of PVA/ZIF-8/GA Composites}

The X-ray diffraction (XRD) patterns of ZIF-8 nanoparticles, PVA/GA, and the PVA/ZIF8/GA composites are represented in Figure $2 \mathrm{a}$. The strong XRD peaks observed at $7.3^{\circ}(011)$, $10.3^{\circ}(002), 12.7^{\circ}(112), 14.8^{\circ}(022), 16.4^{\circ}(013), 18.0^{\circ}(222), 24.5^{\circ}(233)$, and $26.8^{\circ}(134)$ were attributed to the ZIF-8 particles [38]. Increasing the ZIF-8 content in the PVA matrix, the intensities of the corresponding ZIF-8 peaks increased in the composite membrane without peak shifts. Moreover, the ZIF-8 phase structure was well preserved after being mixed with PVA polymeric solution.

The FTIR spectra of the pure PVA and GA-crosslinked PVA membranes are represented in Figure 2b. The pure PVA spectrum displayed sharp peaks at 1088 and $1332 \mathrm{~cm}^{-1}$, represented by the stretching and deformation vibration of $\mathrm{C}-\mathrm{O}-\mathrm{C}$ groups. The peak at $1650 \mathrm{~cm}^{-1}$ is attributed to the stretching vibration of $-\mathrm{OH}$ groups that are sensitive to intermolecular interaction [39] or C-H bending vibration in PVA [40]. In addition, the peak at $1707 \mathrm{~cm}^{-1}$ denotes the stretching vibration of carbonyl $(\mathrm{C}=\mathrm{O})$ groups from the existence of acetate groups [41]. The characteristics vibration at 2860 and $2928 \mathrm{~cm}^{-1}$ attributed to the asymmetric and symmetric stretching vibration of $\mathrm{C}-\mathrm{H}$ from alkyl groups [25]. The broad peak at $3328 \mathrm{~cm}^{-1}$ represents the axial deformation of the $-\mathrm{OH}$ groups involved in PVA intra- and intermolecular hydrogen bonding $[42,43]$. In the case of the PVA/GA membrane, the decreasing FTIR peak intensity is due to the formation of ether linkages and acetal rings [25]. This resulted from the reaction between the $\mathrm{OH}$ groups of PVA and the aldehyde groups of GA $[40,44]$.

The high-resolution C1s XPS spectra of PVA (prepared according to [31]), PVA/GA, and PVA/40.5\%ZIF-8, without and with GA-crosslinked membranes, are shown in Figure 2c-f. The XPS peaks of the PVA at 284.5, 285.8, and $289 \mathrm{eV}$ were assigned to C-C $(47 \%), \mathrm{C}-\mathrm{O}(49 \%)$, and $\mathrm{C}=\mathrm{O}(3 \%)$ bonds, respectively, and correspond with the reported literature [45]. After GA-crosslinked with PVA, the C-C (45\%) bond intensity decreased and increased the hydrophilic groups of $\mathrm{C}-\mathrm{O}(51 \%)$ and $\mathrm{C}=\mathrm{O}$ bonds $(4 \%)$, as shown in Figure $2 \mathrm{~d}$. Moreover, the $\mathrm{C} 1 \mathrm{~s}$ peak shifted towards higher binding energies in the PVA/GA sample. The aldehyde groups participated in the reaction with hydroxyl groups in PVA polymeric chains. Thereby, the $\mathrm{C}-\mathrm{O} / \mathrm{C}=\mathrm{O}$ bond of acetal and ether linkage percentage increased, which confirms the successful GA crosslinking with PVA segments. After the addition of ZIF-8 nanofillers in the PVA or PVA/GA samples, only the C-C and C-O bonds were visible, and the $\mathrm{C}=\mathrm{O}$ bond disappeared (Figure 2e,f) due to complete PVA alcoholysis [45]. This might be attained with higher nanofiller loadings (40.5\%) and ZIF-8 particle interfacial bonding/interaction with PVA segments. The C-O percentage of PVA/ZIF-8/GA (47\%) was increased higher than that of the PVA/ZIF-8 (44\%) composite due to increased bond stability between the aldehyde groups and PVA polymeric matrix. 

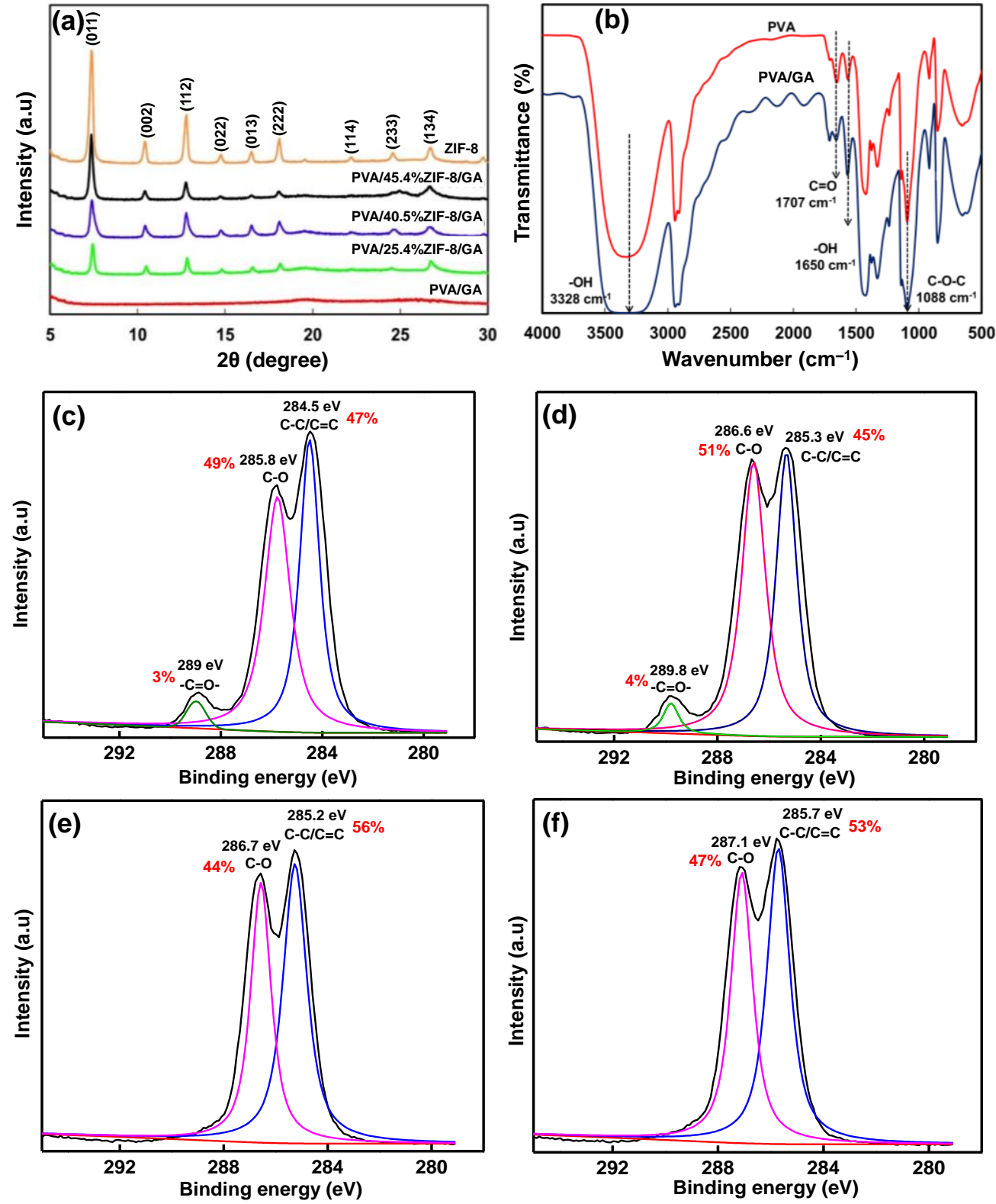

Figure 2. (a) X-ray diffraction patterns of ZIF-8 nanoparticles and PVA/GA and PVA/ZIF-8/GA composites (25.4\%, 40.5\%, and 45.4\% ZIF-8 loadings); (b) FTIR spectra of pure PVA membrane (prepared as in [31]) and GA-crosslinked PVA composite; and XPS detailed scans of C1s of (c) PVA, (d) PVA/GA, (e) PVA/40.5\%ZIF-8 (prepared as in [31]), and (f) PVA/40.5\%ZIF-8/GA composites.

\subsection{Mechanical Analysis of Nanocomposite Membranes}

The mechanical behaviors of PVA/ZIF-8/GA composites $(0 \%, 25.4 \%, 40.5 \%$, and $45.4 \%$ ZIF-8 loadings) are presented in Figure 3 and Table 1 . With the addition of ZIF-8 into the PVA matrix, the composite membranes significantly lost ductility, and the elongation was reduced by two orders of magnitude at 25.4-45.4\% ZIF-8 loads (Table 1). The tensile strength (5.65 to 7.49 MPa) and Young's modulus (29.5 to 313.3 MPa) were increased from pure crosslinked PVA to $40.5 \%$ ZIF-8 load but decreased at $45.4 \%$ loading, as shown in Table 1. At this high ZIF-8 load, the composite became brittle. Compared to other MMMs incorporated with dry fillers [37,38], this water-based synthesis and composite preparation technique can tolerate higher filler concentration. Thereby, the mechanical properties of these composites were higher than those reported in the literature on PVA@10\%ZIF-8 composite (4.5 MPa vs. $21 \mathrm{MPa})$ [46]. 

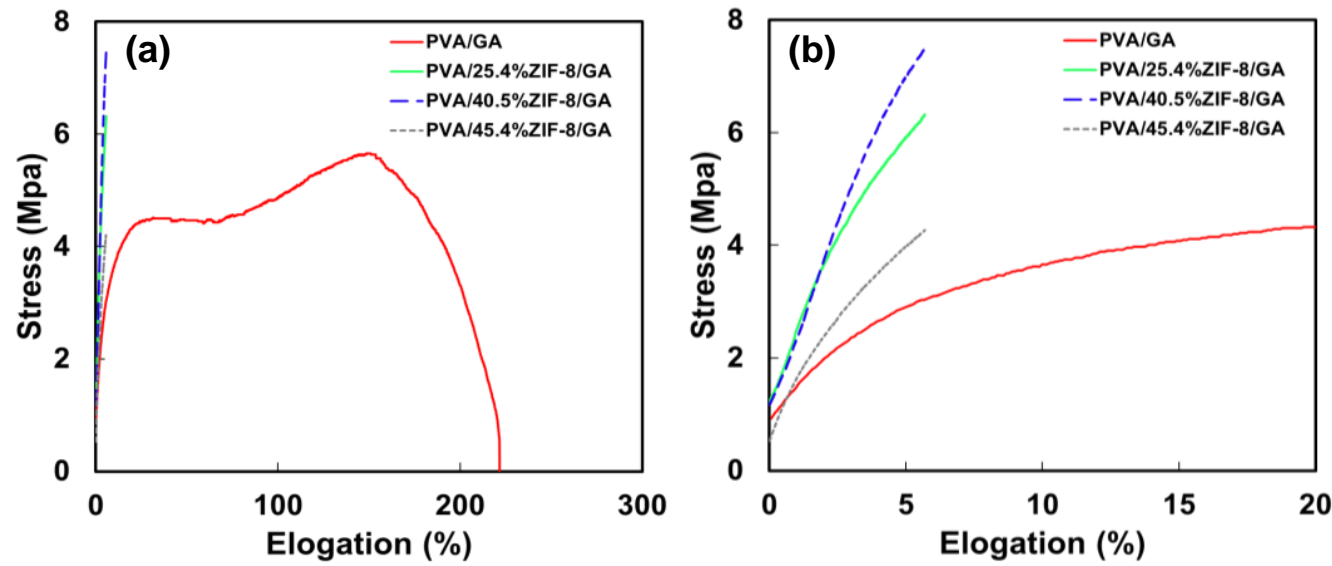

Figure 3. Stress-strain curves of PVA and PVA/ZIF-8 with GA crosslinking in (a) entire and (b) low elongation ranges.

Table 1. Structural, mechanical, and electrochemical properties of the PVA/GA and the PVA/ZIF8/GA composites at $30^{\circ} \mathrm{C}$.

\begin{tabular}{ccccc}
\hline ZIF-8 Load in Membrane & $\mathbf{0 \%}$ & $\mathbf{2 5 . 4 0 \%}$ & $\mathbf{4 0 . 5 0 \%}$ & $\mathbf{4 5 . 4 0 \%}$ \\
\hline Tensile strength (MPa) & 5.65 & 6.32 & 7.49 & 4.27 \\
Elongation (\%) & 228 & 5.69 & 5.69 & 5.69 \\
Young's modulus (MPa) & 29.5 & 264 & 313 & 123 \\
Polymer crystallinity (\%) & 36.5 & 30.2 & 29.1 & 29.4 \\
Alkali uptake ( $\left.\mathrm{g} \mathrm{g}^{-1}\right)$ & 0.81 & 0.89 & 0.98 & 1.08 \\
Through-plane ionic conductivity & 1.15 & 1.35 & 1.39 & 1.41 \\
$\quad\left(\times 10^{-2} \mathrm{~S} \mathrm{~cm}^{-1}\right)$ & 9.63 & 1.66 & 0.54 & 1.12 \\
Methanol permeability (10 & $\left.\mathrm{cm}^{2} \mathrm{~s}^{-1}\right)$ & 9020 & 25,700 & 12,400 \\
Selectivity $\left(\mathrm{Ss} \mathrm{cm}^{-3}\right)$ & 1190 & &
\end{tabular}

\subsection{Crystallinity, Alkali Uptake, and Ionic Conductivity}

The polymeric crystalline nature of PVA/ZIF-8/GA composites were determined using DSC, and the data are represented in Table 1. All samples exhibited endothermic peaks at $215-225{ }^{\circ} \mathrm{C}$. The PVA/GA polymer showed a crystallinity of $36.5 \%$, which was slightly lower than that of pure PVA film (38.1\% [31]). The chemical crosslinking of GA with PVA chains reduced the hydroxyl groups in the PVA and weakened hydrogen bond formation, thereby decreasing the chain packing and the degree of crystallinity [44]. When increasing the ZIF-8 nanofiller loadings in the PVA/GA matrix, the polymeric crystallinity of the composite membranes decreased. The polymeric crystallinity of PVA/40.5\%ZIF-8/GA was decreased to $29.15 \%$, which was the lowest (Table 1) among the tested samples. The amorphous region was increased with the addition of ZIF- 8 because the fillers inhibited the polymeric backbones from aligning [16]. Yang et al. also reported that higher montmorillonite ceramic nanofiller loads in the GA-crosslinked PVA showed an augmented amorphous phase [47], which is in line with our findings. The crystallinity of the PVA composite membrane depends on the PVA molecular weight. For the low-molecular-weight PVA (89-98 k Da) composites containing fumed silica fillers, the polymer crystallinity decreased from $51.5 \%$ to $44.1 \%$ and $41.4 \%$ at $20 \%$ and $30 \%$ filler loadings, respectively [18]. In the case of high-molecular-weight PVA (146-186 k Da) composites, the crystallinity decreased from $38.1 \%$ (pure PVA) to $34.2 \%$ at $25.4 \%$ nanofiller load [31]. The higher molecular-weight PVA exhibits longer chains and more chain entanglement and is less likely to form crystallites. The increased amorphous region and free volume properties are beneficial for ionic conduction [48].

The swelling resistance in alkaline solution is an important factor to determine the stability of AEMs. The PVA/GA membrane shows higher swelling ratio of $51.5 \%$. Incorporating $25.4 \%$ ZIF-8 into the polymeric matrix, the volume swelling behavior slightly 
decreased (swelling ratio of $49 \%$ ). Increasing the ZIF-8 loads to $40.5-45.4 \%$ exhibited negligible volume swelling changes $(<1.4 \%)$ and confirmed the dimensional stability. Much literature used dried ZIF nanofiller powders (1-10 wt.\%) into polymeric matrices and obtained moderate to high swelling ratios (22-320\%) [49-52]. Such highly swollen composites may suffer from dimensional changes and weakened mechanical strength. In this study, the ZIF-8 nanoparticles were synthesized using the water-based method [30], and the as-prepared aqueous suspension was directly added to the hydrophilic PVA solution. This improved the chemical compatibility of the solid fillers and the polymer, resulting in the homogeneous nanofiller distribution (as shown in Figure 1) in the composite. Such uniformity was affixed with the help of the GA crosslinker to suppress polymer chain mobility. The combined water-base ZIF-8 synthesis and GA crosslinking approaches result in good swelling resistance, which is beneficial for alkaline fuel cell applications.

The PVA/GA membrane absorbed $0.81 \mathrm{~g} \mathrm{~g}^{-1} \mathrm{KOH}$ molecules per weight of the polymer (Table 1). The alkali uptakes of the GA-crosslinked PVA samples were slightly lower than that for the un-crosslinked sample ( 0.81 vs. $0.92 \mathrm{~g} \mathrm{~g}^{-1}$, Table 1 and [31]). The crosslinked chains lost flexibility, and swelling was prohibited. Increasing the ZIF-8 nanofiller content in the PVA polymeric matrix, the adsorbed $\mathrm{KOH}$ in the composites increased from 0.89 to $1.08 \mathrm{~g} \mathrm{~g}^{-1}$ (Table 1). This was because of the enhanced polymeric amorphous region in the PVA/ZIF8/GA composite membranes, which enabled intermolecular interaction and promoted $\mathrm{KOH}$ uptake. It has also been reported that nanofiller addition to the composite membrane played an important role in preventing polymer chain alignment and ion diffusion [53].

The membrane resistance at $30^{\circ} \mathrm{C}$ could be measured with an AC impedance analyzer, and the through-plane conductivity is summarized in Table 1 . The ionic conductivity of PVA/GA was $1.15 \times 10^{-2} \mathrm{~S} \mathrm{~cm}^{-1}$ and $1.35-1.41 \times 10^{-2} \mathrm{~S} \mathrm{~cm}^{-1}$ for the PVA/ZIF8/GA composites. The improvement in ionic conductivity by increasing ZIF-8 nanofiller content resulted from the higher alkali uptakes and ionic transport rates within the polymer electrolytes.

\subsection{Alcohol Permeability of Nanocomposite Membranes}

The methanol permeability of PVA/ZIF-8/GA composites $(0 \%, 25.4 \%, 40.5 \%$, and $45.4 \%$ ZIF- 8 loadings) are studied using $2 \mathrm{M}$ methanol. The results are represented in Table 1. The methanol permeability of PVA/GA was $9.6 \times 310^{-6} \mathrm{~cm}^{2} \mathrm{~s}^{-1}$, whereas the permeability decreased with increasing ZIF-8 nanofillers concentrations in the GA-crosslinked PVA up to $40.5 \%$ load $\left(0.54 \times 10^{-6} \mathrm{~cm}^{2} \mathrm{~s}^{-1}\right)$. This confirms that the diffusion coefficient or the solubility of methanol was reduced by increasing the ZIF-8 content in the PVA/GA matrix [31]. The increased polymeric amorphous region at a higher ZIF-8 load facilitated water and hydroxide ion passage but limited methanol transport. We reported that PVA composites demonstrate increased free volume upon filler addition as the result of both increased free volume hole intensity and size. However, the enlarged free volume hole size was not sufficient for alcohol passage [53]. In addition, the ZIF-8 pore size was $0.34 \mathrm{~nm}$ [54], which might permit hydroxide (ionic radius of $0.11 \mathrm{~nm}$ [55]) and water molecules (kinetic diameter of $0.296 \mathrm{~nm}$ [56]) to pass through while blocking methanol (kinetic diameter of $0.38 \mathrm{~nm}[56])$.

Note that as the ZIF-8 content was increased to $45.5 \%$, the methanol permeability was raised to $1.12 \times 10^{-6} \mathrm{~cm}^{2} \mathrm{~s}^{-1}$. The filler aggregates (shown in previous sections) form voids or cracks, allowing methanol molecules to breakthrough. Nevertheless, this load was much higher than those of other fillers incorporated into the polymeric matrix. The allowed filler load is discussed in the last section.

The methanol permeability data for the un-crosslinked PVA/ZIF-8 composites [31] were adopted for comparison. Because the crosslinked PVA showed a lower polymer crystallinity (due to chain confinement) than the un-crosslinked pure PVA film (36.5\% vs. $38.1 \%$ [31]), the methanol was transported faster in the crosslinked sample $\left(9.63 \times 10^{-6}\right.$ $\mathrm{cm}^{2} \mathrm{~s}^{-1}$ vs. $4.28 \times 10^{-6} \mathrm{~cm}^{2} \mathrm{~s}^{-1}$ [31]). Upon filler addition, the permeability trend started to shift. In the $25.4 \%$ ZIF- 8 composites, the crosslinked and un-crosslinked composites 
showed comparable methanol permeabilities $\left(1.66 \times 10^{-6} \mathrm{~cm}^{2} \mathrm{~s}^{-1}\right.$ vs. $1.48 \times 10^{-6} \mathrm{~cm}^{2}$ $\mathrm{s}^{-1}$ [31]), owing to confined chain movement in the chemical crosslinker (GA) and physical steric hindrance (nanofillers). As the filler content was raised to $40.5 \%$ and $45.4 \%$, the methanol permeability was further suppressed in the crosslinked composites, and the methanol transport rates were only half those of their un-crosslinked counterparts.

\subsection{Selectivity of Nanocomposite Membranes}

The conductivity-to-permeability selectivity of the GA-crosslinked PVA/ZIF-8 composites are represented in Figure 4 and Table 1 . The values of un-crosslinked samples in Figure 4 are taken from previous work [31]. At low nanofiller loadings (0-25.4\%), both un-crosslinked and GA-crosslinked samples have a similar range of selectivity values. When increasing the ZIF-8 nanofiller concentrations to $40.5 \%$ and $45.4 \%$, the selectivity of GA-crosslinked composites increased to 1.5-2 fold than those of the un-crosslinked samples. The selectivity reached the highest value at $40.5 \%$ ZIF- 8 loading, primarily due to the lowest permeability.

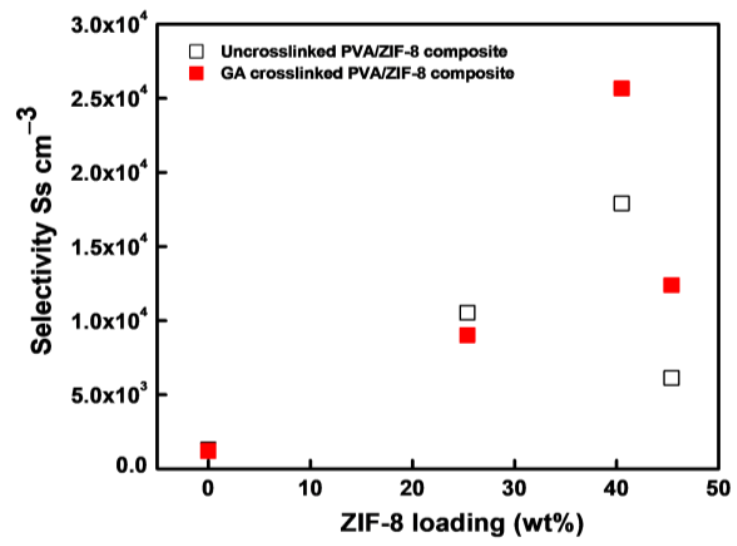

Figure 4. Selectivity of un-crosslinked (data from [31]) and GA-crosslinked PVA/ZIF-8 composites $\left(0 \%, 25.4 \%, 40.5 \%\right.$, and $45.4 \%$ ZIF-8 loadings) at $30{ }^{\circ} \mathrm{C}$.

Yang et al. [47] reported that 15-20\% of montmorillonite-ceramic-nanofillers-loaded GA-crosslinked PVA samples exhibited lower ionic conductivity than the composite with $<10 \%$ loading. This was due to poor dispersion (chunks) or large aggregation of nanofillers in the polymeric matrix restricting the ionic transport pathways. It was also reported that incorporating $>5 \%$ of nanofillers in the PVA polymer matrix leads to high filler agglomeration due to poor nanofiller dispersion capability and obtained non-uniform composite for alkaline fuel cells $[57,58]$. Remarkably, the present water phase technique shows improved selectivity due to the uniform distribution of ZIF-8 nanofillers in the polymeric matrix, even at higher concentrations (up to $40.5 \%$ of ZIF-8 loadings). The results further confirmed that the aqueous phase method could overcome the nanofiller aggregation problem in the MMMs for high-filler loadings, as compared with solid nanofiller incorporation methods $[47,59,60]$.

\subsection{Alkaline Stability of Nanocomposite Membranes}

The PVA/GA and the PVA/40.5\%ZIF-8/GA composites were placed in $6 \mathrm{M}$ alkaline solution for various time periods to measure the long-term alkaline stability in terms of the through-plane ionic conductivity. The samples were evacuated at $30^{\circ} \mathrm{C}$ after immersion in $6 \mathrm{M}$ alkaline solution for $24 \mathrm{~h}$ and $168 \mathrm{~h}$ to observe the change in ionic conductivity, as shown in Figure 5. After $168 \mathrm{~h}$ in alkaline solution, the PVA/GA membrane had 3.04\% ionic conductivity loss when compared with the initial conductivity. With the 40.5\% ZIF-8 content in the PVA matrix, the ionic conductivity showed almost negligible change $(0.19 \%)$ during the $168 \mathrm{~h}$ in the alkaline solution. The addition of ZIF-8 nanoparticles resulted in a compact physical network structure among the PVA/GA molecular chains, decreasing 
the swelling of PVA chains and molecular relaxation. Moreover, the present work of GAcrosslinked samples maintained ionic conductivity, as compared with those counterparts without crosslinking [31]. Without GA crosslinking, the pristine PVA and PVA/40.5\%ZIF-8 composites showed drastically decreased conductivity (31.28\% and $14.14 \%$ loss [31]). The loss of ionic conductivity was owing to less $\mathrm{KOH}$ being retained on the membrane and the weakening of the backbone of the polymeric matrix [22,34,61]. With the addition of a GA crosslinker, the polymer chain dissolution was inhibited, and the composite membrane confined structure was able to retain $\mathrm{KOH}$ in the PVA matrix and maintain strong stability in alkaline.

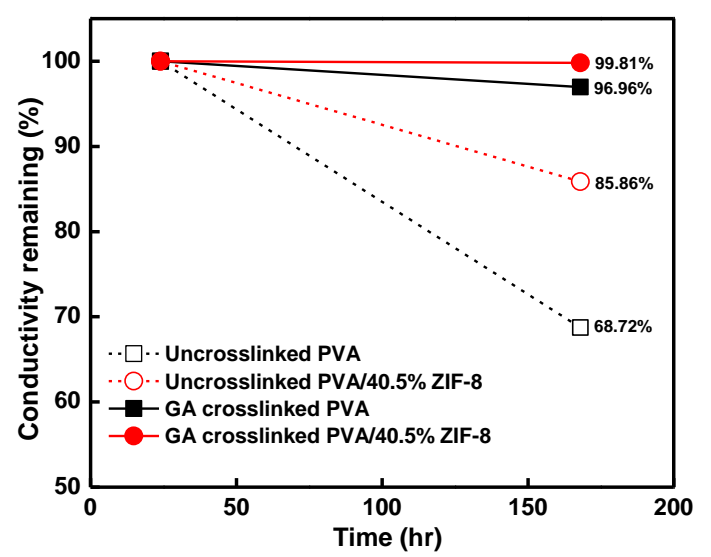

Figure 5. Relative through-plane conductivity decay of un-crosslinked (data from [31]) and GAcrosslinked PVA and PVA/40.5\%ZIF-8 composites after 168-h alkaline treatment time.

\subsection{Single-Cell Performance of PVA/ZIF-8/GA Composites}

The DAMFC performance of single cells using the PVA/GA and PVA/ZIF-8/GA composites at $30{ }^{\circ} \mathrm{C}$ and $60{ }^{\circ} \mathrm{C}$ is displayed in Figure $6 \mathrm{a}-\mathrm{h}$. The composites containing ZIF-8 loads of $0 \%, 25.4 \%, 40.5 \%$, and $45.4 \%$ resulted in open-circuit voltage $\left(\mathrm{V}_{\mathrm{oc}}\right)$ values of $0.69,0.61,0.68$, and $0.49 \mathrm{~V}$, respectively, at $30^{\circ} \mathrm{C}$. Their resultant maximum power densities $\left(\mathrm{P}_{\max }\right)$ were $40.5,80.3,81.7$, and $66.3 \mathrm{~mW} \mathrm{~cm}^{-2}$, respectively. The DAMFC performance using the PVA/40.5\%ZIF-8/GA composite exhibited the highest $\mathrm{V}_{\mathrm{oc}}$ and $\mathrm{P}_{\max }$ among the tested samples. As the temperature was raised to $60{ }^{\circ} \mathrm{C}$, the $\mathrm{V}_{\mathrm{oc}}(0.80,0.69,0.76$, and $0.58 \mathrm{~V})$ and $\mathrm{P}_{\max }\left(67.7,178.4,190.5\right.$, and $\left.150.2 \mathrm{~mW} \mathrm{~cm}^{-2}\right)$ values were improved. The higher operating temperature could promote electrochemical kinetic reactions [62]. Moreover, the ionic conductivity was higher with increasing temperature (Table 1). The slope of the ohmic loss region was lower at the higher temperature, and the cell was able to sustain itself at higher current densities (Figure 6a-d vs. Figure 6e,f).

The DAMFC performance using composites of different ZIF-8 contents in the PVA/GA at 30 and $60{ }^{\circ} \mathrm{C}$ is displayed in Figure 7 . At both temperatures, the cell voltage and power density were increased with increasing ZIF-8 loads until 40.5\%. The PVA/40.5\%ZIF-8/GA composite shows the highest $\mathrm{P}_{\max }$ of $82 \mathrm{~mW} \mathrm{~cm}^{-2}$ and $191 \mathrm{~mW} \mathrm{~cm}^{-2}$ at $30{ }^{\circ} \mathrm{C}$ and $60{ }^{\circ} \mathrm{C}$. Increasing the temperature could improve the $\mathrm{P}_{\max }$ values of all the samples due to the faster electrochemical kinetic reaction rates and lower electrical resistance in the single fuel cell $[28,63]$. The optimal load of ZIF-8 nanoparticles was $40.5 \%$, which was associated with the highest selectivity, as shown in Figure 5. When the ZIF-8 load was increased further to $45.4 \%$, the power density decreased. This was due to the defects caused by the non-homogeneous ZIF-8 distribution in the composite (Figure 1h). This resulted in a high methanol cross-over rate. Similar behavior was also reported when increasing nanofillers load in the PVA/CNT composite [63]. The reduced conductivity-to-methanol permeability ratio (selectivity in Figure 4 ) was parallel to the reduced $P_{\max }$ values. The miscibility of aqueous ZIF-8 and PVA solutions seems to reach an optimal level at $40.5 \%$ ZIF-8 load. This high ZIF-8 load was not easily achieved conventionally by mixing PVA solutions with dry filler particles because fillers tend to form aggregates in the MMMs [53]. 

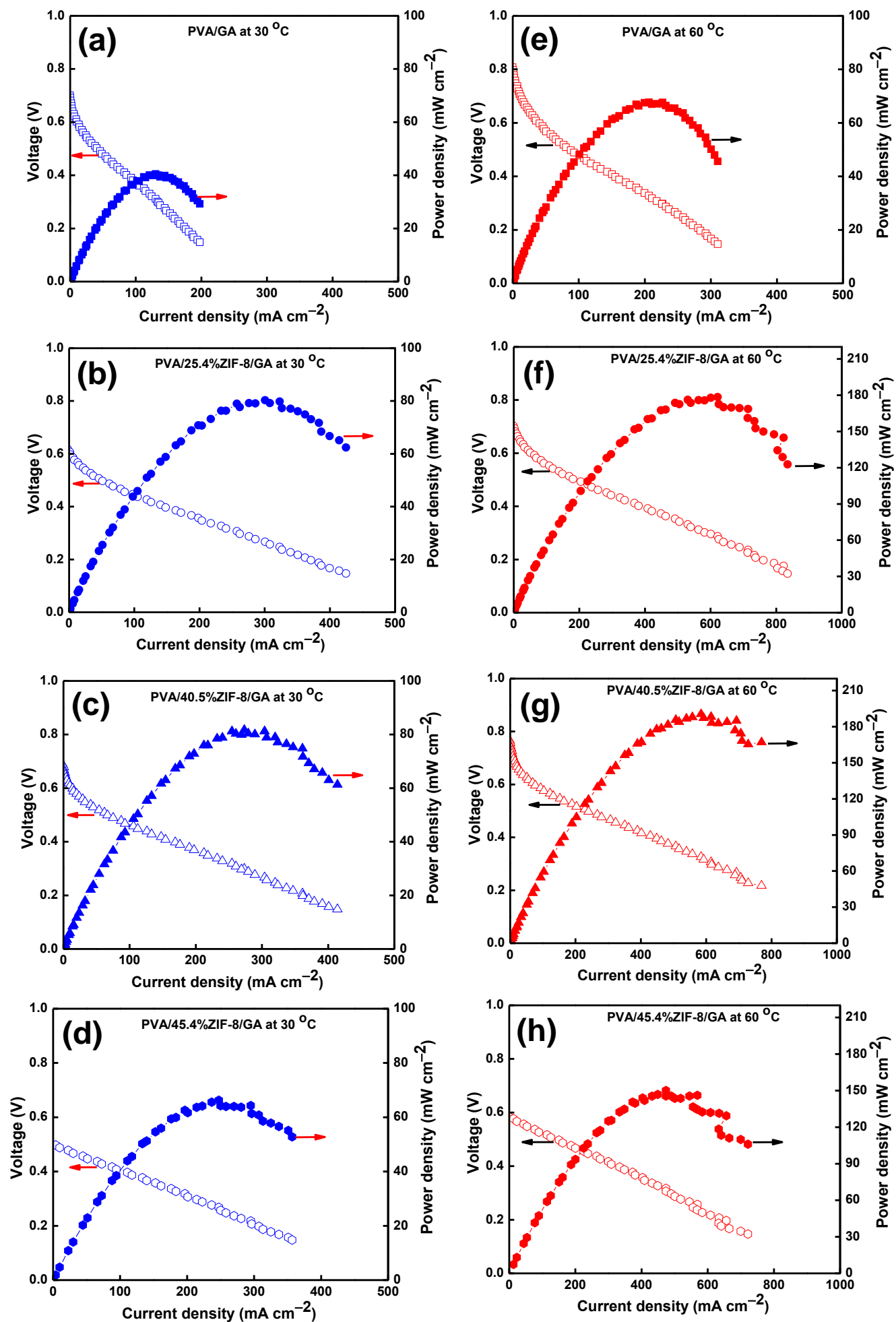

Figure 6. Single-cell performance using PVA/GA, PVA/25.4\%ZIF-8/GA, PVA/40.5\%ZIF-8/GA, and PVA/45.4\%ZIF-8/GA composite electrolytes: (a-d) cell voltage and power density at $30^{\circ} \mathrm{C}$, and $(\mathbf{e}-\mathbf{h})$ cell voltage and power density at $60^{\circ} \mathrm{C}$. The open symbols marked with left arrows show cell voltage data (value and unit in left $\mathrm{Y}$ axis) and the closed symbols with right arrows correspond to power density values (right $\mathrm{Y}$ axis). 


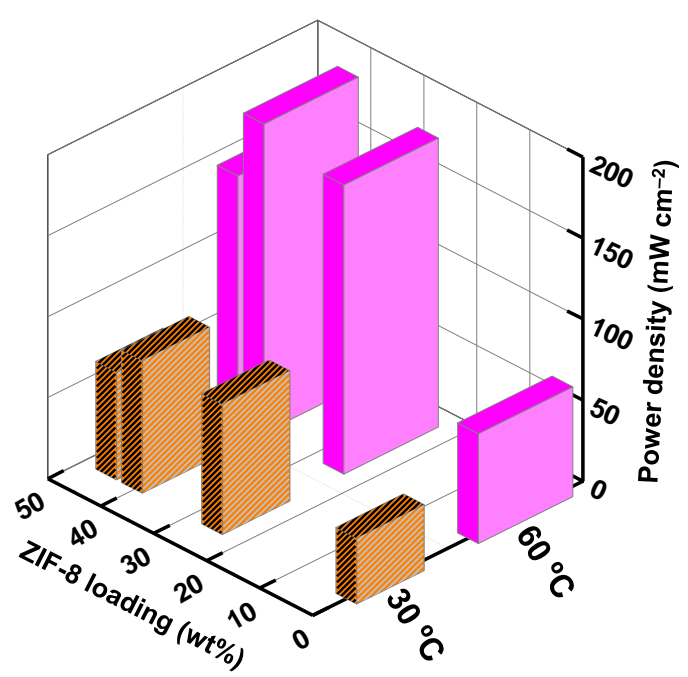

Figure 7. Peak-power density comparison of PVA/ZIF-8/GA composites $(0 \%, 25.4 \%$, $40.5 \%$, and $45.4 \%$ ZIF-8 loadings) at $30^{\circ} \mathrm{C}$ and $60^{\circ} \mathrm{C}$.

The PVA/40.5\%ZIF-8/GA resulted in a higher $\mathrm{P}_{\max }$ by $10 \%$ than the uncrosslinked PVA/ $40.5 \%$ ZIF- 8 composite (190.5 vs. $173.2 \mathrm{~mW} \mathrm{~cm}^{-2}$ [31]) at $60^{\circ} \mathrm{C}$. The pre-crosslinking treatment was beneficial for good membrane characteristics and cell performance. In our previous work [26], QPVA/GO- $\mathrm{Fe}_{3} \mathrm{O}_{4}$ was cast and dried, and the film was postcrosslinked with GA. Although the post-crosslinking treatment enhanced the polymer amorphous phase and mechanical stability, the fuel cell performance was sacrificed [26]. It seems that the pre-crosslinking step before the aqueous ZIF-8/PVA mixture water phase is preferred as this process saves energy to dry ZIF-8 and GA can fully crosslink the polymer chains prior to film casting.

\subsection{Fuel Cell Performance Comparison}

Table 2 summarizes our DAMFC peak-power density literature data from the fuel cells using MMMs and their corresponding pristine membranes [17,26,29,31,62-69]. It is very clear that incorporating nanofillers into a polymeric matrix to form fuel cell electrolytes can significantly improve power generation. We reported that these fillers provide steric hindrance to interrupt semi-crystalline polymer chain alignment, generating increased polymeric fractional free volumes (FFV) at the expense of polymer crystallinity. For the PVA/fumed silica (FS) composites with 0-30\% loads, the FFV increased from 1.7 to $2.8 \%$ [48] and crystallinity decreased from 51 to $41 \%$ [18]. Even at a minute amount $(0.05 \%)$ carbon nanotube (CNT) load, the PVA/CNT membrane exhibited an FFV of $3.53 \%$, increased from $2.48 \%$ of pure PVA film [63]. At the same time, the polymer crystallinity dropped from $42 \%$ to 38\% [70]. For crosslinked quaternized PVA/quaternized chitosan (QPVA/Qchitosan) composite at $5 \%$ load, the FFV increased from 2.0 to $3.1 \%$, and crystallinity decreased from 9.8 to $6.4 \%[17,66]$. In the present work, the FFV of the crosslinked composite increase from $4.45 \%$ (without ZIF- 8 addition) to $8.36 \%$ is accompanied with a crystallinity decrease from 37 to $29 \%$ (Table 1 ).

Detailed examination of the FFV characteristics using positron annihilation lifetime spectroscopy reveals that these composites demonstrated higher free volume hole densities than their pure polymer counterparts $[17,48]$, contributing to the increased FFV. The free volume hole size may be slightly enlarged in the PVA/FS or shrunk in the crosslinked QPVA/Qchitosan composites. These hole sizes (radius of 2.2-2.7 $\mathrm{A}$ [17,48]) can provide sufficient pathways for hydroxide ions (radius of $1.1 \AA$ ) and water diffusion [69] but not for larger methanol penetrant. Consequently, the nanocomposite ionic conductivities were improved, whereas the fuel cross-over rates were prohibited. The overall effect of adding nanofillers into polymers was the reduced ohmic losses shown in the polarization curves and increased peak-power densities. 
Table 2. Peak-power density $\left(\mathrm{P}_{\max }\right)$ comparison of DAMFCs using polymeric composites and pure membranes (data in parentheses under $\mathrm{P}_{\max }$ column), reported from the authors' group at $60{ }^{\circ} \mathrm{C}$.

\begin{tabular}{|c|c|c|c|c|}
\hline Electrolytes & $\begin{array}{l}\text { Filler Loading } \\
\text { (wt.\%) }\end{array}$ & $\begin{array}{l}\text { Peak-power Density } \\
\left(P_{\max }\right)\left(\mathrm{mW} \mathrm{cm}^{-2}\right)\end{array}$ & $\begin{array}{c}\text { Pmax Increment } \\
\text { Compared with Pure } \\
\text { Sample }(\%)\end{array}$ & Source \\
\hline PBI/GO spin coated & 0.6 & $140(110)$ & 27 & Yu et al. [62] \\
\hline $\mathrm{PBI} / \mathrm{GO}$ & 1 & $231(225)$ & 2.7 & Chang et al. [67] \\
\hline $\mathrm{PBI} / \mathrm{GO}-\mathrm{Fe}_{3} \mathrm{O}_{4}$ & 0.2 & $176(145)$ & 21 & Kumar et al. [68] \\
\hline PVA/CNTs & 0.05 & $39(27)$ & 45 & Pan et al. [69] \\
\hline PVA/CNTs & 0.05 & $39(20)$ & 95 & Lue et al. [63] \\
\hline QPVA/Qchitosan & 5 & $73(38)$ & 92 & Liao et al. [17] \\
\hline QPVA/fumed silica & 5 & $88(36)$ & 146 & Kumar et al. [65] \\
\hline QPVA/CTAB coated $\mathrm{LaFeO}_{3}$ & 0.1 & $272(155)$ & 76 & Kumar et al. [29] \\
\hline $\begin{array}{l}\mathrm{QPVA} / \mathrm{GO}-\mathrm{Fe}_{3} \mathrm{O}_{4} / \mathrm{GA} \\
\text { with magnetic field }^{\mathrm{a}}\end{array}$ & 0.1 & $55(22)$ & 147 & Lin et al. [26] \\
\hline QPVA/Chitosan/GA ${ }^{\mathrm{b}}$ & 10 & $58(40)$ & 46 & Li et al. [64] \\
\hline QPVA/Qchitosan/GA ${ }^{b}$ & 5 & $73(40)$ & 83 & Liao et al. [66] \\
\hline QPVA/Qchitosan/GA ${ }^{\mathrm{b}}$ & 20 & $50(40)$ & 25 & Liao et al. [66] \\
\hline PVA/ZIF-8 & 40.5 & $173(81)$ & 114 & Hsu et al. [31] \\
\hline PVA/ZIF-8/GA ${ }^{c}$ & 40.5 & $191(68)$ & 181 & This work \\
\hline
\end{tabular}

${ }^{a}$ Membrane: post-crosslinked; $\mathrm{Pt} / \mathrm{C}\left(5 \mathrm{mg} \mathrm{cm}^{-2}\right)$; Pt-Ru/C $\left(6 \mathrm{mg} \mathrm{cm}^{-2}\right) .{ }^{\mathrm{b}}$ Membrane: pre-crosslinked; $\mathrm{Pt} / \mathrm{C}(5$ $\left.\mathrm{mg} \mathrm{cm}{ }^{-2}\right) ; \mathrm{Pt}-\mathrm{Ru} / \mathrm{C}\left(6 \mathrm{mg} \mathrm{cm}^{-2}\right)$. ${ }^{\mathrm{c}}$ This work: pre-crosslinked; Pt/C $\left(1 \mathrm{mg} \mathrm{cm}^{-2}\right) ; \mathrm{Pt}-\mathrm{Ru} / \mathrm{C}\left(2 \mathrm{mg} \mathrm{cm}^{-2}\right)$. GA: glutaraldehyde. QPVA: quaternized PVA. CNTs: carbon nanotubes. Qchitosan: quaternized chitosan particles. PBI: polybenzimidazole. GO: graphene oxide. $\mathrm{GO}-\mathrm{Fe}_{3} \mathrm{O}_{4}$ : graphene oxide decorated with $\mathrm{Fe}_{3} \mathrm{O}_{4}$ nanoparticles.

Note that optimal nanofiller loads strongly depend on the filler geometry and the compatibility with the base polymer. For zero-dimension fillers, such as FS and Qchitosan, $20-30 \%$ loads are probably reaching the upper boundary, and higher loads beyond this threshold tend to form cracks and defects due to dispersion heterogeneity. For one- and twodimensional nanofillers (e.g., CNTs, GO, etc.), large surface areas allow much interaction (van der Waals force, electrostatic interactions, hydrogen bonding, ion-dipole, etc.) with polymers [40,71], and the optimal loads are only a few percent or even tenths of a percent. This water-based synthesis limited the aggregation problems, even at higher nanofiller loads $(40.5 \%)$, and improved the homogeneous distribution of ZIF-8 nanofillers in the polymeric matrix without any cracks or defects (Figure 1). The optimized PVA/40.5\%ZIF8/GA composite shows $181 \% \mathrm{P}_{\max }$ improvement, as compared with the pristine PVA/GA sample. The attained $\mathrm{P}_{\max }$ values in this work were higher than those previously reported for GA-crosslinked electrolytes (Table 2) under similar operating conditions.

\section{Conclusions}

In this work, the water-based synthesis method was used to prepare ZIF-8 nanoparticle suspension, which was mixed directly into a PVA solution (without an intermediate particle drying step) to achieve uniform nanofiller dispersion. This structure was retained using the GA crosslinker. This approach produces composites containing high ZIF-8 concentrations (up to $40.5 \%$ ). The ZIF-8 nanofiller homogeneity in the composites and defect- and crackfree structure were clearly observed using FESEM and EDS analyses. The combination of uniform nanofiller distribution and crosslinker affixation improved swelling resistance, maintained polymer chain confinement, retarded methanol cross-over, retained mechanical robustness, and prevented conductivity decay of the composites.

An increased polymeric amorphous region in the composite was reported and positively correlated to $\mathrm{KOH}$ uptake and ionic conductivity. Methanol permeability was suppressed in the composites and reached a minimum at the highest (40.5\%) ZIF-8 load. The resultant selectivities of GA-crosslinked composites were 1.5-2 times higher than those of the un-crosslinked samples. The higher ZIF-8 loads (40.5\%) in the crosslinked composite exhibited negligible volume swelling ratios and good dimensional stability. The optimal ZIF-8 load was $40.5 \%$ in the composite, and the achieved $P_{\max }$ was $190.5 \mathrm{~mW} \mathrm{~cm}{ }^{-2}$ at $60{ }^{\circ} \mathrm{C}$. The obtained $\mathrm{P}_{\max }$ value is $181 \%$ higher than that of pure PVA/GA membrane. These swollen-resistant and stable solid electrolytes are promising in alkaline fuel cell applications. 
Supplementary Materials: The following supporting information can be downloaded at: https:/ www. mdpi.com/article/10.3390/nano12050865/s1. Figure S1: Nitrogen adsorption-desorption isotherm of ZIF-8 nanoparticles; Figure S2: Photographic images of (a) PVA/GA, (b) PVA/40.5\%ZIF-8/GA, and (c) PVA/45.4\%ZIF-8/GA composite membranes; Figure S3: EDX mapping micrographs showing Zn distribution in (a) PVA/25.4\%ZIF-8/GA, (b) PVA/40.5\%ZIF-8/GA, and (c) PVA/45.4\%ZIF-8/GA composite membranes; Table S1: Comparison of acid and alkaline-based PVA composite electrolytes for direct methanol fuel cells; Table S2: The weight percentages (determined from EDS) of PVA/ZIF-8/GA composites with various ZIF-8 loadings.

Author Contributions: P.-Y.H.: Formal analysis, Validation, Data curation, Writing-original draft. T.-Y.H.: Formal analysis, Data curation. S.R.K.: Validation, Investigation, Writing-original draft, Writing-review and editing. K.C.-W.W.: Conceptualization, Validation, Resources. S.J.L.: Conceptualization, Resources, Formal analysis, Methodology, Supervision, Writing-review and editing, Funding acquisition. All authors have read and agreed to the published version of the manuscript.

Funding: This research was funded by the Ministry of Science and Technology (MOST 108-2221-E182-021-MY3 and MOST 109-2811-E-182-507-MY2), Taiwan.

Institutional Review Board Statement: Not applicable.

Informed Consent Statement: Not applicable.

Data Availability Statement: Not applicable.

Conflicts of Interest: The authors declare no conflict of interest.

\section{References}

1. Olah, G.A. Beyond oil and gas: The methanol economy. Angew. Chem. Int. Ed. Engl. 2005, 44, 2636-2639. [CrossRef] [PubMed]

2. Lee, S.J.; Theerthagiri, J.; Nithyadharseni, P.; Arunachalam, P.; Balaji, D.; Kumar, A.M.; Madhavan, J.; Mittal, V.; Choi, M.Y. Heteroatom-doped graphene-based materials for sustainable energy applications: A review. Renew. Sustain. Energy Rev. 2021, 143, 110849. [CrossRef]

3. Theerthagiri, J.; Murthy, A.P.; Lee, S.J.; Karuppasamy, K.; Arumugam, S.R.; Yu, Y.; Hanafiah, M.M.; Kim, H.-S.; Mittal, V.; Choi, M.Y. Recent progress on synthetic strategies and applications of transition metal phosphides in energy storage and conversion. Ceram. Int. 2021, 47, 4404-4425. [CrossRef]

4. Couture, G.; Alaaeddine, A.; Boschet, F.; Ameduri, B. Polymeric materials as anion-exchange membranes for alkaline fuel cells. Prog. Polym. Sci. 2011, 36, 1521-1557. [CrossRef]

5. Wu, Y.; Liu, X.; Yang, F.; Zhou, L.L.; Yin, B.; Wang, P.; Wang, L. Achieving high power density and excellent durability for high temperature proton exchange membrane fuel cells based on crosslinked branched polybenzimidazole and metal-organic frameworks. J. Membr. Sci. 2021, 630, 119288. [CrossRef]

6. Robertson, N.J.; Kostalik, I.H.A.; Clark, T.J.; Mutolo, P.F.; Abruña, H.D.; Coates, G.W. Tunable High Performance Cross-Linked Alkaline Anion Exchange Membranes for Fuel Cell Applications. J. Am. Chem. Soc. 2010, 132, 3400-3404. [CrossRef]

7. Liu, G.; Tsen, W.-C.; Jang, S.-C.; Hu, F.; Zhong, F.; Zhang, B.; Wang, J.; Liu, H.; Wang, G.; Wen, S.; et al. Composite membranes from quaternized chitosan reinforced with surface-functionalized PVDF electrospun nanofibers for alkaline direct methanol fuel cells. J. Membr. Sci. 2020, 611, 118242. [CrossRef]

8. Chu, X.; Liu, J.; Miao, S.; Liu, L.; Huang, Y.; Tang, E.; Liu, S.; Xing, X.; Li, N. Crucial role of side-chain functionality in anion exchange membranes: Properties and alkaline fuel cell performance. J. Membr. Sci. 2021, 625, 119172. [CrossRef]

9. Wang, Y.; Qiao, X.; Liu, M.; Liu, L.; Li, N. The effect of -NH- on quaternized polybenzimidazole anion exchange membranes for alkaline fuel cells. J. Membr. Sci. 2021, 626, 119178. [CrossRef]

10. Gamburzev, S.; Petrov, K.; Appleby, A.J. Silver-carbon electrocatalyst for air cathodes in alkaline fuel cells. J. Appl. Electrochem. 2002, 32, 805-809. [CrossRef]

11. Al-Saleh, M.A.; Gültekin, S.; Al-Zakri, A.S.; Celiker, H. Effect of carbon dioxide on the performance of Ni/PTFE and Ag/PTFE electrodes in an alkaline fuel cell. J. Appl. Electrochem. 1994, 24, 575-580. [CrossRef]

12. Shen, S.Y.; Zhao, T.S.; Xu, J.B.; Li, Y.S. Synthesis of PdNi catalysts for the oxidation of ethanol in alkaline direct ethanol fuel cells. J. Power Sources 2010, 195, 1001-1006. [CrossRef]

13. Zakaria, Z.; Kamarudin, S.K. A review of quaternized polyvinyl alcohol as an alternative polymeric membrane in DMFCs and DEFCs. Int. J. Energy Res. 2020, 44, 6223-6239. [CrossRef]

14. Lue, S.J.; Mahesh, K.P.O.; Wang, W.-T.; Chen, J.-Y.; Yang, C.-C. Permeant transport properties and cell performance of potassium hydroxide doped poly(vinyl alcohol)/fumed silica nanocomposites. J. Membr. Sci. 2011, 367, 256-264. [CrossRef]

15. Karim, N.A.; Kamarudin, S.K. An overview on non-platinum cathode catalysts for direct methanol fuel cell. Appl. Energy 2013, 103, 212-220. [CrossRef] 
16. Lue, S.J.; Wang, W.-T.; Mahesh, K.P.O.; Yang, C.-C. Enhanced performance of a direct methanol alkaline fuel cell (DMAFC) using a polyvinyl alcohol/fumed silica/KOH electrolyte. J. Power Sources 2010, 195, 7991-7999. [CrossRef]

17. Liao, G.-M.; Yang, C.-C.; Hu, C.-C.; Pai, Y.-L.; Lue, S.J. Novel quaternized polyvinyl alcohol/quaternized chitosan nano-composite as an effective hydroxide-conducting electrolyte. J. Membr. Sci. 2015, 485, 17-29. [CrossRef]

18. Lue, S.J.; Chen, J.-Y.; Yang, J.M. Crystallinity and Stability of Poly(vinyl alcohol)-Fumed Silica Mixed Matrix Membranes. J. Macromol. Sci. Part B 2007, 47, 39-51. [CrossRef]

19. Maiti, J.; Kakati, N.; Lee, S.H.; Jee, S.H.; Viswanathan, B.; Yoon, Y.S. Where do poly(vinyl alcohol) based membranes stand in relation to Nafion ${ }^{\circledR}$ for direct methanol fuel cell applications? J. Power Sources 2012, 216, 48-66. [CrossRef]

20. Praptowidodo, V.S. Influence of swelling on water transport through PVA-based membrane. J. Mol. Struct. 2005, 739, 207-212. [CrossRef]

21. Guo, R.; Hu, C.; Li, B.; Jiang, Z. Pervaporation separation of ethylene glycol/water mixtures through surface crosslinked PVA membranes: Coupling effect and separation performance analysis. J. Membr. Sci. 2007, 289, 191-198. [CrossRef]

22. Merle, G.; Hosseiny, S.S.; Wessling, M.; Nijmeijer, K. New cross-linked PVA based polymer electrolyte membranes for alkaline fuel cells. J. Membr. Sci. 2012, 409-410, 191-199. [CrossRef]

23. Diaz, L.A.; Coppola, R.E.; Abuin, G.C.; Escudero-Cid, R.; Herranz, D.; Ocón, P. Alkali-doped polyvinyl alcoholPolybenzimidazole membranes for alkaline water electrolysis. J. Membr. Sci. 2017, 535, 45-55. [CrossRef]

24. Yeom, C.-K.; Lee, K.-H. Pervaporation separation of water-acetic acid mixtures through poly(vinyl alcohol) membranes crosslinked with glutaraldehyde. J. Membr. Sci. 1996, 109, 257-265. [CrossRef]

25. Rudra, R.; Kumar, V.; Kundu, P.P. Acid catalysed cross-linking of poly vinyl alcohol (PVA) by glutaraldehyde: Effect of crosslink density on the characteristics of PVA membranes used in single chambered microbial fuel cells. RSC Adv. 2015, 5, 83436-83447. [CrossRef]

26. Lin, J.-S.; Ma, W.-T.; Shih, C.-M.; Yu, B.-C.; Teng, L.-W.; Wang, Y.-C.; Cheng, K.-W.; Chiu, F.-C.; Lue, S.J. Reorientation of Magnetic Graphene Oxide Nanosheets in Crosslinked Quaternized Polyvinyl Alcohol as Effective Solid Electrolyte. Energies 2016, 9, 1003. [CrossRef]

27. Lin, J.-S.; Kumar, S.R.; Ma, W.-T.; Shih, C.-M.; Teng, L.-W.; Yang, C.-C.; Lue, S.J. Gradiently distributed iron oxide@graphene oxide nanofillers in quaternized polyvinyl alcohol composite to enhance alkaline fuel cell power density. J. Membr. Sci. 2017, 543, 28-39. [CrossRef]

28. Wu, J.-F.; Lo, C.-F.; Li, L.-Y.; Li, H.-Y.; Chang, C.-M.; Liao, K.-S.; Hu, C.-C.; Liu, Y.-L.; Lue, S.J. Thermally stable polybenzimidazole/carbon nano-tube composites for alkaline direct methanol fuel cell applications. J. Power Sources 2014, $246,39-48$. [CrossRef]

29. Kumar, S.R.; Ma, W.-T.; Lu, H.-C.; Teng, L.-W.; Hsu, H.-C.; Shih, C.-M.; Yang, C.-C.; Lue, S.J. Surfactant-assisted perovskite nanofillers incorporated in quaternized poly (vinyl alcohol) composite membrane as an effective hydroxide-conducting electrolyte. Energies 2017, 10, 615. [CrossRef]

30. Deng, Y.H.; Chen, J.T.; Chang, C.H.; Liao, K.S.; Tung, K.L.; Price, W.E.; Yamauchi, Y.; Wu, K.C. A Drying-Free, Water-Based Process for Fabricating Mixed-Matrix Membranes with Outstanding Pervaporation Performance. Angew. Chem. Int. Ed. Engl. 2016, 55, 12793-12796. [CrossRef]

31. Hsu, P.-Y.; Hu, T.-Y.; Kumar, S.R.; Chang, C.-H.; Wu, K.C.-W.; Tung, K.-L.; Lue, S.J. Highly zeolite-loaded polyvinyl alcohol composite membranes for alkaline fuel-cell electrolytes. Polymers 2018, 10, 102. [CrossRef] [PubMed]

32. Salavagione, H.J.; Martínez, G.; Gómez, M.A. Synthesis of poly(vinyl alcohol)/reduced graphite oxide nanocomposites with improved thermal and electrical properties. J. Mater. Chem. 2009, 19, 5027. [CrossRef]

33. ASTM. ASTM D882-02 Standard Test Method for Tensile Properties of Thin Plastic Sheeting; ASTM International: West Conshohocken, PA, USA, 2002.

34. Ma, W.-T.; Kumar, S.R.; Hsu, C.-T.; Shih, C.-M.; Tsai, S.-W.; Yang, C.-C.; Liu, Y.-L.; Lue, S.J. Magnetic field-assisted alignment of graphene oxide nanosheets in a polymer matrix to enhance ionic conduction. J. Membr. Sci. 2018, 563, 259-269. [CrossRef]

35. Lee, Y.-R.; Jang, M.-S.; Cho, H.-Y.; Kwon, H.-J.; Kim, S.; Ahn, W.-S. ZIF-8: A comparison of synthesis methods. Chem. Eng. J. 2015, 271, 276-280. [CrossRef]

36. García-Palacín, M.; Martínez, J.I.; Paseta, L.; Deacon, A.; Johnson, T.; Malankowska, M.; Téllez, C.; Coronas, J. Sized-Controlled ZIF-8 Nanoparticle Synthesis from Recycled Mother Liquors: Environmental Impact Assessment. ACS Sustain. Chem. Eng. 2020, 8, 2973-2980. [CrossRef] [PubMed]

37. Amirilargani, M.; Sadatnia, B. Poly(vinyl alcohol)/zeolitic imidazolate frameworks (ZIF-8) mixed matrix membranes for pervaporation dehydration of isopropanol. J. Membr. Sci. 2014, 469, 1-10. [CrossRef]

38. Barooah, M.; Mandal, B. Synthesis, characterization and CO2 separation performance of novel PVA/PG/ZIF-8 mixed matrix membrane. J. Membr. Sci. 2019, 572, 198-209. [CrossRef]

39. Yang, W.; Qi, G.; Kenny, J.M.; Puglia, D.; Ma, P. Effect of Cellulose Nanocrystals and Lignin Nanoparticles on Mechanical, Antioxidant and Water Vapour Barrier Properties of Glutaraldehyde Crosslinked PVA Films. Polymers 2020, 12, 1364. [CrossRef]

40. Aladejana, J.T.; Wu, Z.; Li, D.; Guelifack, K.; Wei, W.; Wang, X.A.; Xie, Y. Facile Approach for Glutaraldehyde Cross-Linking of PVA/Aluminophosphate Adhesives for Wood-Based Panels. ACS Sustain. Chem. Eng. 2019, 7, 18524-18533. [CrossRef]

41. Mallakpour, S.; Rashidimoghadam, S. Preparation, characterization, and in vitro bioactivity study of glutaraldehyde crosslinked chitosan/poly(vinyl alcohol)/ascorbic acid-MWCNTs bionanocomposites. Int. J. Biol. Macromol. 2020, 144, 389-402. [CrossRef] 
42. Cholant, C.M.; Rodrigues, M.P.; Peres, L.L.; Balboni, R.D.; Krüger, L.U.; Placido, D.N.; Flores, W.H.; Gündel, A.; Pawlicka, A.; Avellaneda, C.O. Study of the conductivity of solid polymeric electrolyte based on PVA/GA blend with addition of acetic acid. J. Solid State Electrochem. 2020, 24, 1867-1875. [CrossRef]

43. Mansur, H.A.; Sadahira, C.M.; Souza, A.N.; Mansur, A.A. FTIR spectroscopy characterization of poly (vinyl alcohol) hydrogel with different hydrolysis degree and chemically crosslinked with glutaraldehyde. Mater. Sci. Eng. C 2008, 28, 539-548. [CrossRef]

44. Alfayyadh, A.A.; Lotfy, S.; Basfar, A.; Khalil, M.I. Influences of poly (vinyl alcohol) molecular weight and carbon nanotubes on radiation crosslinking shape memory polymers. Prog. Nat. Sci. 2017, 27, 316-325. [CrossRef]

45. Zhang, W.; Zhang, Z.; Wang, X. Investigation on surface molecular conformations and pervaporation performance of the poly(vinyl alcohol) (PVA) membrane. J. Colloid Interface Sci. 2009, 333, 346-353. [CrossRef]

46. Fan, X.; Yu, L.; Li, L.; Yang, C.; Wen, J.; Ye, X.; Cheng, J.; Hu, Y. Characterization and application of zeolitic imidazolate framework-8@polyvinyl alcohol nanofibers mats prepared by electrospinning. Mater. Res. Express 2017, 4, 026404. [CrossRef]

47. Yang, C.-C.; Lee, Y.-J.; Yang, J.M. Direct methanol fuel cell (DMFC) based on PVA/MMT composite polymer membranes. J. Power Sources 2009, 188, 30-37. [CrossRef]

48. Lue, S.J.; Lee, D.-T.; Chen, J.-Y.; Chiu, C.-H.; Hu, C.-C.; Jean, Y.; Lai, J.-Y. Diffusivity enhancement of water vapor in poly(vinyl alcohol)-fumed silica nano-composite membranes: Correlation with polymer crystallinity and free-volume properties. J. Membr. Sci. 2008, 325, 831-839. [CrossRef]

49. Wei, Z.; Liu, Q.; Wu, C.; Wang, H.; Wang, H. Viscosity-driven in situ self-assembly strategy to fabricate cross-linked ZIF-90/PVA hybrid membranes for ethanol dehydration via pervaporation. Sep. Purif. Technol. 2018, 201, 256-267. [CrossRef]

50. Zhang, H.; Wang, Y. Poly (vinyl alcohol)/ZIF-8-NH2 mixed matrix membranes for ethanol dehydration via pervaporation. AIChE J. 2016, 62, 1728-1739. [CrossRef]

51. Xiong, Y.; Deng, N.; Wu, X.; Zhang, Q.; Liu, S.; Sun, G. De novo synthesis of amino-functionalized ZIF-8 nanoparticles: Enhanced interfacial compatibility and pervaporation performance in mixed matrix membranes applying for ethanol dehydration. Sep. Purif. Technol. 2021, 285, 120321. [CrossRef]

52. Wang, S.; Huang, Z.; Ru, X.; Wang, J. Effects of different porous fillers on interfacial properties of poly (vinyl alcohol) hybrid films J. Appl. Polym. Sci. 2021, 138, 50641. [CrossRef]

53. Lo, C.-F.; Wu, J.-F.; Li, H.-Y.; Hung, W.-S.; Shih, C.-M.; Hu, C.-C.; Liu, Y.-L.; Lue, S.J. Novel polyvinyl alcohol nanocomposites containing carbon nano-tubes with Fe3O4 pendants for alkaline fuel cell applications. J. Membr. Sci. 2013, 444, 41-49. [CrossRef]

54. Dong, G.; Li, H.; Chen, V. Challenges and opportunities for mixed-matrix membranes for gas separation. J. Mater. Chem. A 2013, 1,4610-4630. [CrossRef]

55. Marcus, Y. Volumes of aqueous hydrogen and hydroxide ions at 0 to 200 degrees C. J. Chem. Phys. 2012, 137, 154501. [CrossRef]

56. Bowen, T.C.; Noble, R.D.; Falconer, J.L. Fundamentals and applications of pervaporation through zeolite membranes. J. Membr. Sci. 2004, 245, 1-33. [CrossRef]

57. Yang, C.-C.; Chiu, S.-J.; Chien, W.-C.; Chiu, S.-S. Quaternized poly (vinyl alcohol)/alumina composite polymer membranes for alkaline direct methanol fuel cells. J. Power Sources 2010, 195, 2212-2219. [CrossRef]

58. Yang, C.-C.; Chiu, S.-S.; Kuo, S.-C.; Liou, T.-H. Fabrication of anion-exchange composite membranes for alkaline direct methanol fuel cells. J. Power Sources 2012, 199, 37-45. [CrossRef]

59. Rambabu, G.; Bhat, S.D.; Figueiredo, F.M. Carbon nanocomposite membrane electrolytes for direct methanol fuel cells-A concise review. Nanomaterials 2019, 9, 1292. [CrossRef]

60. Narducci, R.; Sgreccia, E.; Knauth, P.; Di Vona, M.L. Anion Exchange Membranes with 1D, 2D and 3D Fillers: A Review. Polymers 2021, 13, 3887. [CrossRef]

61. Yang, C.-C. Synthesis and characterization of the cross-linked $\mathrm{PVA} / \mathrm{TiO}_{2}$ composite polymer membrane for alkaline DMFC. J. Membr. Sci. 2007, 288, 51-60. [CrossRef]

62. Yu, B.-C.; Wang, Y.-C.; Lu, H.-C.; Lin, H.-L.; Shih, C.-M.; Kumar, S.R.; Lue, S.J. Hydroxide-ion selective electrolytes based on a polybenzimidazole/graphene oxide composite membrane. Energy 2017, 134, 802-812. [CrossRef]

63. Lue, S.J.; Pan, W.-H.; Chang, C.-M.; Liu, Y.-L. High-performance direct methanol alkaline fuel cells using potassium hydroxideimpregnated polyvinyl alcohol/carbon nano-tube electrolytes. J. Power Sources 2012, 202, 1-10. [CrossRef]

64. Li, P.-C.; Liao, G.M.; Kumar, S.R.; Shih, C.-M.; Yang, C.-C.; Wang, D.-M.; Lue, S.J. Fabrication and Characterization of Chitosan Nanoparticle-Incorporated Quaternized Poly(Vinyl Alcohol) Composite Membranes as Solid Electrolytes for Direct Methanol Alkaline Fuel Cells. Electrochim. Acta 2016, 187, 616-628. [CrossRef]

65. Rajesh Kumar, S.; Juan, C.-H.; Liao, G.-M.; Lin, J.-S.; Yang, C.-C.; Ma, W.-T.; You, J.-H.; Jessie Lue, S. Fumed Silica Nanoparticles Incorporated in Quaternized Poly(Vinyl Alcohol) Nanocomposite Membrane for Enhanced Power Densities in Direct Alcohol Alkaline Fuel Cells. Energies 2015, 9, 15. [CrossRef]

66. Liao, G.-M.; Yang, C.-C.; Hu, C.-C.; Teng, L.-W.; Hsieh, C.-H.; Lue, S.J. Optimal loading of quaternized chitosan nanofillers in functionalized polyvinyl alcohol polymer membrane for effective hydroxide ion conduction and suppressed alcohol transport. Polymers 2018, 138, 65-74. [CrossRef]

67. Chang, W.-T.; Chao, Y.-H.; Li, C.-W.; Lin, K.-L.; Wang, J.-J.; Kumar, S.R.; Lue, S.J. Graphene oxide synthesis using microwaveassisted vs. modified Hummer's methods: Efficient fillers for improved ionic conductivity and suppressed methanol permeability in alkaline methanol fuel cell electrolytes. J. Power Sources 2019, 414, 86-95. [CrossRef] 
68. Kumar, S.R.; Wang, J.-J.; Wu, Y.-S.; Yang, C.-C.; Lue, S.J. Synergistic role of graphene oxide-magnetite nanofillers contribution on ionic conductivity and permeability for polybenzimidazole membrane electrolytes. J. Power Sources 2020, 445, 227293. [CrossRef]

69. Pan, W.-H.; Lue, S.J.; Chang, C.-M.; Liu, Y.-L. Alkali doped polyvinyl alcohol/multi-walled carbon nano-tube electrolyte for direct methanol alkaline fuel cell. J. Membr. Sci. 2011, 376, 225-232. [CrossRef]

70. Huang, C.-C.; Liu, Y.-L.; Pan, W.-H.; Chang, C.-M.; Shih, C.-M.; Chu, H.-Y.; Chien, C.-H.; Juan, C.-H.; Lue, S.J. Direct borohydride fuel cell performance using hydroxide-conducting polymeric nanocomposite electrolytes. J. Polym. Sci. Part B Polym. Phys. 2013, 51, 1779-1789. [CrossRef]

71. Bhattacharya, M. Polymer nanocomposites-A comparison between carbon nanotubes, graphene, and clay as nanofillers. Materials 2016, 9, 262. [CrossRef] 